\title{
Las sales solubles en el deterioro de rocas monumentales.Revisión bibliográfica
}

\author{
C.M. GROSSI* y R.M. ESBERT * * \\ Dpto. de Geología. Universidad de Oviedo
}

Fecha de recepción: 13-V-94

ESPAÑA

Palabras clave: Sales solubles, rocas monumentales, deterioro, conservación, sulfatos, cloruros, nitratos, carbonatos.

\section{RESUMEN}

Se resalta la importancia que las sales solubles tienen en el deterioro/conservación de las rocas monumentales. Se relacionan aquellas sales que con mayor frecuencia aparecen en los monumentos y la procedencia de las mismas. A su vez se lleva a cabo una revisión de los daños originados por dichas sales y de los mecanismos de alteración desarrollados. Finalmente, se indica el diferente comportamiento de cada tipo de sal y su distribución en las paredes de los edificios.
Key words: Soluble salts. monumental stones, deterioration, conservation, sulphates, chlorides, nitrates, carbonates

\section{ABSTRACT}

This paper points out the importance of soluble salts in the deterioration/conservation of monumental stones. The most frequent salts in monuments as well as their sources are referred. A review of the damage caused by these salts and the developed mechanisms of deterioration is also included. Finally, the distinctive behaviour of each type of salt and their distribution on the walls of buildings is shown.

\section{1.-INTRODUCCIÓN}

La alteración de la piedra es un proceso natural e irreversible. Debido a ello, toda edificación construida en piedraestá abocadaa degradarse más o menos rápidamente. En esta degradación, la cristalización de sales solubles en los materiales de edifícación está considerada actualmente comouno de los mecanismos de deterioro más generalizado y efectivo (Sperling y Cooke, 1980; Amoroso y Fassina, 1983; Esbert y Marcos, 1983; Arnold y Zehnder, 1989; etć.).

Así, todos los estudios sobre rocas deterioradas de edificación mencionan, con mayor o menor detalle, los efectos de la cristalización de sales en los elementos de la piedra (Chaterjii et al, 1979; Cuttano et al, 1981; Binda et al, 1985; Alonso, 1986; De Tommasi y Laurenzi Tabasso, 1989; Delgado Rodrigues, 1991, etc.). La presencia de sales solubles no solamente altera el aspecto de la obra cuando se hacen visibles como eflorescencias (en su superficie), sino que pueden originar daños considerables cuando cristalizan en el interior de poros y capilares (Alonso et al, 1987; Fritsch et al, 1988; etc.).

Aunque algunos autores indican que la presencia de sales solubles en los materiales pétreos notiene por qué conducir necesariamente a su deterioro, Arnold y Kueng (1985), señalan que todas las experiencias realizadas en el

\footnotetext{
** Catedrática de Petrología y Geoquímica.

* Becaria Post - Doctoral del Ministerio de Educación y Ciencia en el Building Research Establishment de Garston (U.K).
} 
laboratorio, ponen de manifiesto que todas las sales solubles pueden producir un deterioro muy fuerte en los materiales porosos; cristalizando en sus poros pueden llegar a desmoronar la fábrica de dichos materiales y causar pérdidas irreparables al patrimonio cultural (Zehnder y Arnold, 1989). Así las descamaciones o exfoliaciones, la alveolización, la desagregación o descohesión, las sulfataciones etc. de las piedras de monumentos debidas a la formación de costras, placas, escamas, etc. muestran frecuentemente contenidos elevados en sulfatos, cloruros, nitratos... de calcio, sodio, potasio, y magnesio, principalmente (Furlan y Félix, 1982; Amoroso y Fassina, 1983; Lazzarini y Laurenzi-Tabasso, 1986; etc.).

El efecto de la cristalización de las sales solubles en condiciones naturales, en un material determinado, no sólo depende del tipo de sal y las condiciones ambientales, sino también de las características de la piedra (Grossi, 1992). La combinación de varios factores, entre los que tienen una importancia considerable el tamaño y distribución de los espacios vacíos de la piedra, condicionará la resistencia de la misma a las presiones generadas por las sales durante los procesos de cristalización, hidratación, etc. (Schaffer, 1972).

La identificación y caracterización de las sales que se encuentran en las piedras de edificación deterioradas es muy importante tanto para el diagnóstico de las causas del deterioro como para el planteamiento de las intervenciones de conservación (Charola y Lewin, 1979; Arnold, 1981; etc.).

El fenómeno del deterioro por cristalización de sales es un proceso muy complejo, y aunque existe una literatura abundante que menciona y describe el deterioro por sales,en una gran parte los trabajos son esencialmente cualitativos. En ellos se mencionan algunos fenómenos, como la presión de cristalización, pero sin profundizar en estudios cuantitativos (Lewin, 1989).

\section{2.-TIPOS DE SALES SOLUBLES MÁS FRECUENTES EN ROCAS MONUMENTALES}

Las sales solubles más frecuentes en monumentos son los sulfatos y los cloruros seguidos de los carbonatos, nitratos y, más raramente, nitritos. Los cationes más frecuentes son, por lo general, calcio, sodio, magnesio y potasio (en orden decreciente de frecuencia) (Lazzarini y LaurenziTabasso, 1986). Pueden ser también frecuentes entre los aniones los oxalatos y, entre los cationes, el amonio (Arnold y Zehnder, 1989).

Dentro de estas sales, el mayor número de trabajos bibliográficos relacionados con estudios teóricos y experimentales hace referencia al yeso, halita y sulfatos de sodio y magnesio por ser sales de las más frecuentes y destructivas tanto en las piedras monumentales (Chaterjii, et al, 1979; Lewin, 1981 y 1989; Gauri, 1981; Binda y Baronio, 1984 y 1987; Binda et al, 1985; Gauri et al, 1988; Rossi-Manaressi y Tucci, 1990 y 1991, etc.) como en las rocas de afloramientos naturales (Young, 1987; Matsukura y Kanai, 1988; Smith y McGreevy, 1988; Magee et al, 1988 , etc.).

En la Tabla I se recogen las sales solubles más frecuentes en monumentos según Arnold (1976) y Arnold y Zehnder (1988). En esta tabla se han omitido los carbonatos de calcio y magnesio, porque suelen ser los componentes principales de gran parte de piedras monumentales.

\section{3.- ORIGEN DE LAS SALES SOLUBLES}

Las sales solubles en los edificios, en general, y en los monumentos en particular, son generadas principalmente: a) a partir de iones lixiviados de la alteración de rocas, morteros, ladrillos y otros materiales de construcción; b) procedentes del suelo; c) por depósito de productos atmosféricos y d) generadas por el metabolismo de organismos. También pueden ser generadas por otras fuentes, tales como, por ejemplo, las sales utilizadas para el deshielo de carreteras durante el invierno (cloruros principalmente), que pueden ser transportadas al monumento por el agua o por el viento (Arnold y Zehnder, 1989).

\section{a) Sales procedentes de la alteración química de los materiales}

La alteración de los minerales de la roca o materiales de construcción puede dar lugar a la formación de sales solubles que contribuyen a su vez al deterioro progresivo de la piedra. Por otra parte, las piedras de construcción (tanto naturales como artificiales), así como los morteros de unión, generalmente contienen sales solubles que actúan como agentes alterantes (Arnold, 1981). 
TABLA I

\begin{tabular}{|c|}
\hline Tipos de sales solubles \\
\hline $\begin{array}{l}\text { Cloruros: } \\
\text { NaCl: Halita } \\
\text { Kcl: Silvita }\end{array}$ \\
\hline $\begin{array}{l}\text { Sulfatos: } \\
\mathrm{CaSO}_{4} \cdot 2 \mathrm{H}_{2} \mathrm{O}: \text { Yeso } \\
\mathrm{Na}_{2} \mathrm{SO}_{4}: \text { Thenardita } \\
\mathrm{Na}_{2} \mathrm{SO}_{4} \cdot 10 \mathrm{H}_{2} \mathrm{O}: \text { Mirabilita } \\
\mathrm{K}_{2} \mathrm{SO}_{4}: \text { Arcanita } \\
\left.\mathrm{Na}_{2} \mathrm{Mg}_{\mathrm{SO}}\right)_{2} \cdot 4 \mathrm{H}_{2} \mathrm{O}: \text { Bloedita } \\
\mathrm{MgSO}_{4} \cdot \mathrm{H}_{2} \mathrm{O}: \text { Kieserita } \\
\mathrm{MgSO}_{4} \cdot 6 \mathrm{H}_{2} \mathrm{O}: \text { Hexahidrita } \\
\mathrm{MgSO}_{4} \cdot 7 \mathrm{H}_{2} \mathrm{O}: \text { Epsomita }\end{array}$ \\
\hline $\begin{array}{l}\text { Carbonatos: } \\
\mathrm{Na}_{2} \mathrm{CO}_{3} \cdot \mathrm{H}_{2} \mathrm{O}: \text { Termonatrita } \\
\mathrm{Na}_{2} \mathrm{CO}_{3} \cdot 10 \mathrm{H}_{2} \mathrm{O}: \text { Natrita (natron) }\end{array}$ \\
\hline $\begin{array}{l}\text { Nitratos: } \\
\mathrm{NaNO}_{3}: \text { Nitronatrita } \\
\mathrm{KNO}_{3}: \text { Nitrokalita (nitro) } \\
\mathrm{NH}_{4} \mathrm{NO}_{3}: \text { Nitranmita } \\
\mathrm{Ca}\left(\mathrm{NO}_{3}\right)_{2} \cdot 4 \mathrm{H}_{2} \mathrm{O}: \text { Nitrocalcita }\end{array}$ \\
\hline
\end{tabular}

Sales más comunes en monumentos (Arnold, 1976; Arnold y Zehnder, 1988).

Los carbonatos de Ca y $\mathrm{Mg}$ de las piedras o morteros pueden reaccionar con otras sales o soluciones acuosas, y a su vez, pueden ser productos resultantes de la reacción de otras sales.

Así, la dolomita de las piedras o de los morteros de construcciones antiguas puede reaccionar con sulfatos presentes en las aguas circulantes y dar lugar a sulfato de magnesioy carbonatode calcio según la reacción (Zehnder, 1992):

$$
\mathrm{CaMg}\left(\mathrm{CO}_{3}\right)_{2}+\mathrm{SO}_{4}^{-2} \rightarrow \mathrm{CaCO}_{3}+\mathrm{MgSO}_{4}+\mathrm{CO}_{3}^{-2}
$$

Por otra parte la calcita $\left(\mathrm{CaCO}_{3}\right)$ también puede reaccionar con el $\mathrm{SO}_{2}$ atmosférico en ambientes contaminados y dar lugar a la formación de yeso que cristaliza con dos moléculas de agua $\left(\mathrm{CaSO}_{4} \cdot 2 \mathrm{H}_{2} \mathrm{O}\right)$, según la reacción:

$$
\mathrm{CaCO}_{3}+\mathrm{SO}_{2}+1 / 2 \mathrm{O}_{2}+2 \mathrm{H}_{2} \mathrm{O} \rightarrow \mathrm{CaSO}_{4} \cdot 2 \mathrm{H}_{2} \mathrm{O}+\mathrm{CO}_{2}
$$

La disolución de la calcita $\left(\mathrm{CaCO}_{3}\right)$ de las calizas es una fuente importante de iones $\mathbf{C a}^{+2}$ y $\mathbf{C O}_{3}^{-2}$. El carbonato de calcio es prácticamente insoluble en agua, sin embargo, puede disolverse como bicarbonato cuando el agua, en contacto con la piedra, contiene una cantidad determinada de $\mathrm{CO}_{2}$, procedente de la atmósfera, principalmente en zonas industriales. Este $\mathrm{CO}_{2}$ se disuelve en el agua y forma ácido carbónico $\left(\mathrm{H}_{2} \mathrm{CO}_{3}\right)$ que reacciona con el carbonato formando un bicarbonato, más soluble.

$\frac{\text { Calcita }}{\mathrm{CaCO}_{3}}+\frac{\text { ácido carbónico }}{\mathrm{H}_{2} \mathrm{CO}_{3}} \rightarrow \frac{\text { ión calcio }}{\mathrm{Ca}^{2+}}+\frac{\text { ión bicarbonato }}{2 \mathrm{HCO}_{3}^{-}}$ Cuando un muro comienza a secarse, las sales de bicarbonato migran hacia la superficie y cuando tiene lugar la evaporación, se produce la formación de carbonato cálcico, prácticamente insoluble, que se deposita rápidamente sobre la misma (Press y Siever, 1985; Teutonico, 1988).

Los carbonatos de $\mathrm{K}$ y $\mathrm{Na}$ se forman, generalmente, a partir iones liberados de materiales alcalinos utilizados modernamente en edificios, tales como el cemento portland, o algunos productos de limpieza alcalinos. La mayoría de ellos se introducen como hidróxidos alcalinos y se transforman en sulfatos o carbonatos cuando reaccionan con ácido sulfúrico o carbónico de la atmósfera (Arnold, 1981).

Por otra parte los carbonatos alcalinos pueden reaccionar con el ácido sulfúrico según las siguientes reacciones:

$$
\begin{array}{r}
\mathrm{Na}_{2} \mathrm{CO}_{3}+\mathrm{H}_{2} \mathrm{SO}_{4} \rightarrow \mathrm{Na}_{2} \mathrm{SO}_{4}+\mathrm{CO}_{2}+\mathrm{H}_{2} \mathrm{O} \\
\mathrm{K}_{2} \mathrm{CO}_{3}+\mathrm{H}_{2} \mathrm{SO}_{4} \rightarrow \mathrm{K}_{2} \mathrm{SO}_{4}+\mathrm{CO}_{2}+\mathrm{H}_{2} \mathrm{O}
\end{array}
$$

Según Arnold y Zehnder (1989), $100 \mathrm{~kg}$ de cemento portland con un contenido de $0,1 \%$ de $\mathrm{Na}_{2} \mathrm{O}$ soluble pueden producir $460 \mathrm{~g}$ de natrita $\left(\mathrm{Na}_{2} \mathrm{CO}_{3} \cdot 10 \mathrm{H}_{2} \mathrm{O}\right)$. Si reacciona con el ácido suifúrico en atmósferas contaminadas, puede formar $520 \mathrm{~g}$ de mirabilita $\left(\mathrm{Na}_{2} \mathrm{SO}_{4} \cdot 10 \mathrm{H}_{2} \mathrm{O}\right)$.

También pueden reaccionar con sales existentes en paredes de edificaciones antiguas. (Arnold, 1981).

Algunos materiales usados en la preparación de morteros 
pueden contener pequeñas cantidades de sulfatos que pueden disolverse en el agua y migrar hacia la superficie formando eflorescencias. El uso de yeso en restauraciones también puede dar lugar a la aparición de sulfatos.

Los cloruros, también pueden ser el resultadode impurezas en los materiales utilizados para preparar morteros y estucos.

La alteración química de los silicatos, debida principalmente a hidrólisis, es también una fuente importante de iones.

Los silicatos de rocas magmáticas, en climas húmedotemplados, son atacados por aguas débilmente ácidas. Mediante el contacto con las mismas, reaccionan con los protones de estas aguas disociadas reemplazando los iones compensadores de carga de los minerales $(\mathrm{K}, \mathrm{Na}, \mathrm{Ca})$ y provocando la ruptura de enlaces $\mathrm{Si}-\mathrm{O}-\mathrm{M}^{3+}$ o $\mathrm{Si}-\mathrm{O}-\mathrm{M}^{2+}$, con la liberación de elementos tri y divalentes $\left(\mathrm{M}^{3+}=\mathrm{Al}^{31}\right.$, $\left.\mathrm{Fe}^{3+} ; \mathrm{M}^{2+}=\mathrm{Fe}^{2+}, \mathrm{Mg}^{2+}\right)$

Si se considera el feldespato potásico, se pueden obtener las siguientes reacciones de hidrólisis:

-Si el flujo y la temperatura del agua son elevados se produce una hidrólisis completa:

$$
\mathrm{KAlSi}_{3} \mathrm{O}_{8}+8 \mathrm{H}_{2} \mathrm{O} \rightarrow \mathrm{Al}(\mathrm{OH})_{3}+3 \mathrm{Si}(\mathrm{OH})_{4}+\mathrm{K}^{+}+\mathrm{OH}^{-}
$$

Se eliminan los cationes y la sílice y se forma un hidróxido de aluminio, que puede ser gibbsita o bohemita, según el $\mathrm{pH}$ de la solución.

-Si el proceso es menos intensoy la eliminación de la sílice no es total, la reacción sería la siguiente:

$$
\begin{aligned}
2 \mathrm{KSi}_{3} \mathrm{AlO}_{8}+11 \mathrm{H}_{2} \mathrm{O} \rightarrow & \mathrm{Si}_{2} \mathrm{Al}_{2} \mathrm{O}_{5}(\mathrm{OH})_{4}+4 \mathrm{Si}(\mathrm{OH})_{4}+ \\
+ & 2 \mathrm{~K}^{+}+2 \mathrm{OH}^{-}
\end{aligned}
$$

Formándose un mineral arcilloso de la familia de la caolinita.

-Si el flujoy la intensidad de la hidrólisis son aún menores, se pueden obtener minerales más ricos en sílice, generalmente filosilicatos $2 / 1$. Así se formarían por ejemplo esmectitas trioctaédricas.
En todas estas reacciones se produce una liberación de $\mathrm{K}^{+}$ (Dejou et al, 1977).

Una fuente importante de ion $\mathbf{M g}^{2+}$ son las rocas básicas (Keys y Williams, 1981). Este ion se libera por reacciones de oxidación de piroxenos o hidrólisis de otros minerales máficos.

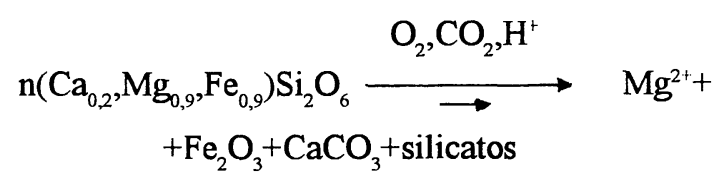

$$
\mathrm{Mg}_{2} \mathrm{SiO}_{4}+4 \mathrm{CO}_{2}+4 \mathrm{H}_{2} \mathrm{O} \longrightarrow 2 \mathrm{Mg}^{2+}+4 \mathrm{HCO}_{3}^{-}+\mathrm{H}_{4} \mathrm{SiO}_{4}
$$

Según estos autores, aparte del magnesio, la alteración química de estas rocas es una importante fuente de $\mathrm{Ca}^{2+}$ y $\mathrm{K}^{+}$y probablemente de carbonatos.

\section{b) Sales procedentes del suelo}

Las aguas procedentes del suelo y que ascienden por las paredes de los edificios por capilaridad son, por logeneral, soluciones salinas más o menos diluidas y contienen iones carbonato, sulfato, cloruro, nitrato, magnesio, calcio, sodio, potasio, y amonio.

Las soluciones procedentes de suelos con asentamientos humanos, suelen estar enriquecidas en nitratos y cloruros. Los nitratos procederían de la acción de microorganismos sobre desechos orgánicos y los cloruros del consumo de cloruro sódico (Arnold y Zehnder, 1989).

Los sulfatosy nitratos, por otra parte, pueden ser abundantes en terrenos dedicados a la agricultura y suelen proceder de los abonos.

\section{c) Depósito de productos atmosféricos}

En la atmósfera, contaminada o no, pueden existir sales en suspensión o pueden estar presentes iones capaces de formar sales solubles.

\section{c.1) Sales de origen marino}

Las sales marinas, mediante movimientos atmosféricos, pueden aparecer lejos de su origen. La cantidad de estas 
sales disminuye con la distancia al océano; pero pueden tener importancia en zonas subdesérticas o desérticas debido a que no se diluyen por el agua de lluvia, lo que favorece su concentración. En zonas más húmedas habrá una eliminación parcial o total de las sales marinas de acuerdo con la solubilidad de las mismas (Auger, 1989).

En la Tabla II, a modo de ejemplo, se muestra la concentración salina del Océano Atlántico y del Mar Mediterráneo.

Estudios realizados por Keys y Williams (1981) sobre distintos afloramientos rocosos en la Región de McMurdo (Antártida) pusieron de manifiesto la distribución de iones con la distancia del mar en dicha región (Fig. 1). El ion $\mathrm{Cl}^{-}$tiende a disminuir con la distancia al mar; es esencialmente de origen marino, ya que es el ion más frecuente en el mar y poco abundante en las rocas de esos afloramientos.

Los iones $\mathrm{Cl}^{-}$y $\mathrm{Na}^{\dagger}$, predominan en las cercanías de la costa. Sin embargo, la concentración relativa de nitratos y sulfatos aumentaba hacia el interior del continente.

En dicha región gran parte de los sulfatos provienen originalmente del mar en forma de aerosoles, ya sea como sulfatos, dióxido de azufre o sulfuro de hidrógeno. Hacia el interior aumenta la relación $\mathrm{SO}_{4}{ }^{2-} / \mathrm{Cl}^{-}$, debido a un aumento en zonas interiores de aerosoles atmosféricos marinos, al tiempo que descienden las contribuciones marinas más directas.

TABLA II

\begin{tabular}{||c|c|c||}
\hline Naturaleza de las sales & O. Atlántico (g/l) & M. Mediterráneo (g/l) \\
\hline $\mathrm{NaCl}$ & 28,14 & 30,76 \\
$\mathrm{KCl}$ & 0,69 & 0,66 \\
$\mathrm{MgCl}_{2}$ & 3,44 & 3,74 \\
$\mathrm{CaSO}_{4}$ & 1,42 & 1,64 \\
$\mathrm{MgSO}_{4}$ & 2,28 & 2,39 \\
& & 39,26 \\
\hline
\end{tabular}

Concentración de sales en el Océano Atlántico y el Mar Mediterraneo (Auger, 1989).

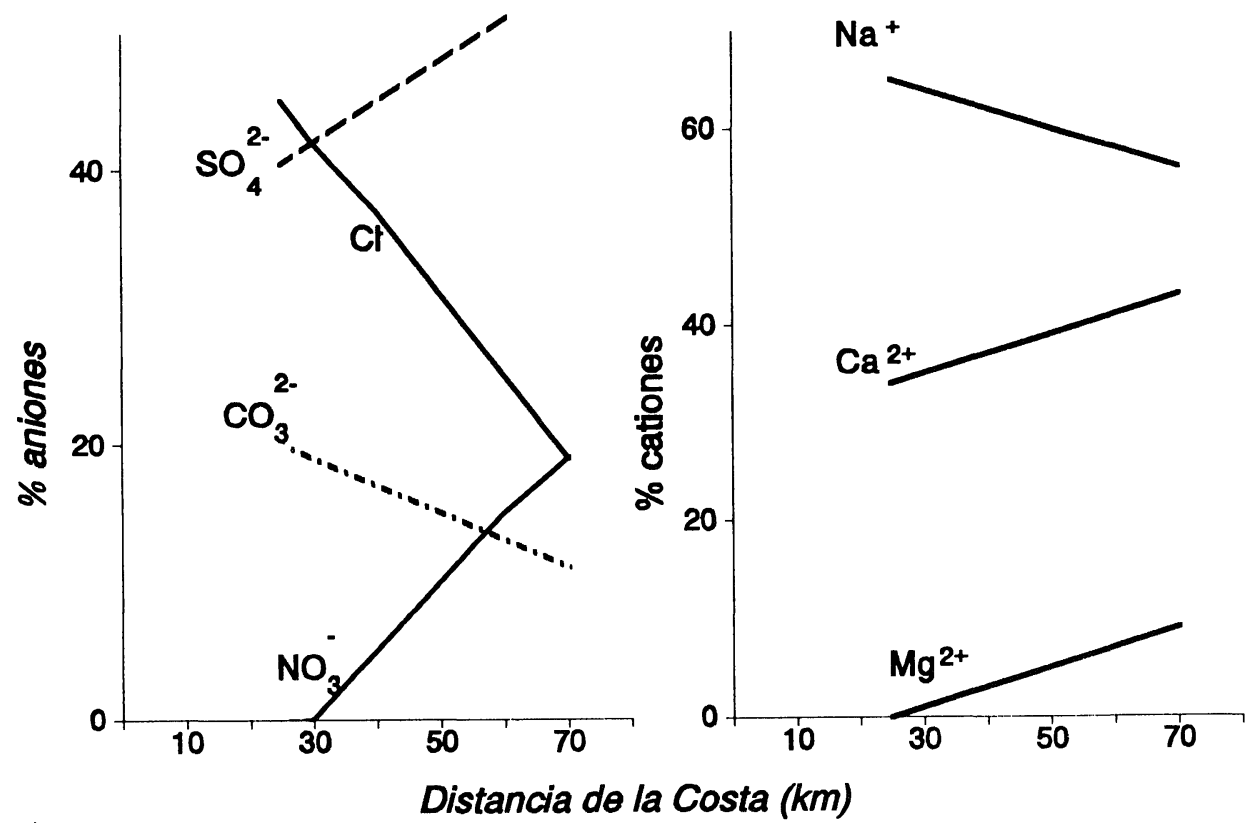

Fig. 1.- Variaciones en concentraciones de iones con la lejanía de la costa en la región de McMurdo (Antártida) (Keys y Williams, 1981). 
Los nitratos también los consideran de procedencia principalmente marina, vía aerosoles. El aumento de iones $\mathrm{NO}_{3}^{-}$con la lejanía del mar, lo explican en base al aumento en la relación entre óxidos de nitrógenoyamoníaco debido, en parte, a la oxidación de este último, que es principalmente de origen marino.

En resumen, el agua de mar es la fuente principal de los cloruros (especialmente de sodio y calcio) presentes en las paredes de los monumentos. También es fuente de sulfatos (especialmente de magnesio) (Teutonico, 1988).

\section{c.2) Depósitos en ambientes contaminados}

Los contaminantes ambientales que pueden encontrarse en los depósitos, pueden proceder de gases tales como $\mathrm{CO}_{2}, \mathrm{SO}_{2}, \mathrm{~N}_{2} \mathrm{O}_{3}, \mathrm{NO}_{2}, \mathrm{NH}_{3}, \mathrm{CH}_{4} \ldots$, líquidos (ácidos, soluciones salinas, etc.) o ser contaminantes sólidos, como óxidos de minerales metálicos, sulfuros, hollín, etc.

Estos depósitos son la fuente principal de los sulfatos.

El efecto mejor conocido es la formación de costras negras de yeso $\left(\mathrm{CaSO}_{4} \cdot 2 \mathrm{H}_{2} \mathrm{O}\right)$ en los edificios a partir del dióxido de azufre, ácido sulfúrico y sulfatos (Arnold y Zehnder, 1989). El yeso se puede formar en el aire y llegar como aerosol o sal a la superficie de los monumentos, o directamente sobre las piedras calcáreas por reacción del carbonato cálcico y el ácido sulfúrico (Esbert y Marcos, 1983; Lazzarini y Laurenzi-Tabasso, 1986).

La combustión de combustibles fósiles conduce a la presencia de dióxido de azufre $\left(\mathrm{SO}_{2}\right)$ en la atmósfera, que reaccionando con el oxígeno se transforma en anhídrido sulfúrico $\left(\mathrm{SO}_{3}\right)$.

$\mathrm{El} \mathrm{SO} \mathrm{S}_{3}$ reacciona con el agua para formar ácido sulfúrico $\left(\mathrm{H}_{2} \mathrm{SO}_{4}\right)$ que ataca al carbonato de calcio de las paredes, que se transforma en sulfato de calcio ${ }^{1}$.

El ácido sulfúrico formado en al aire, también puede se neutralizado por sustancias básicas como el carbonato de calcio, presente en el polvo atmosférico, formando sulfato de calcio dihidratado (yeso) o por el amoníaco $\left(\mathrm{NH}_{3}\right)$ formando sulfato de amonio $\left[\left(\mathrm{NH}_{4}\right)_{2} \mathrm{SO}_{4}\right]$.

Los nitratos también pueden proceder de la contaminación atmosférica; la combustión de combustibles fósiles, especialmente de los motores de automóviles, también puede dar lugar a la formación de varias moléculas orgánicas y óxidos de nitrógeno. Estos óxidos de nitrógeno, mediante una serie de reacciones complejas, forman ácido nítrico $\left(\mathrm{HNO}_{3}\right)$ que, reaccionando con el carbonato cálcico, dan lugar a la formación de nitrato de calcio $\left[\mathrm{Ca}\left(\mathrm{NO}_{3}\right)_{2} \cdot 4 \mathrm{H}_{2} \mathrm{O}\right]$ (Teutonico, 1988).

Ciertos procesos industriales también pueden ser el origen, en ocasiones, de cloruros.

\section{d) Acción de organismos vivos.}

Laacción de los seres vivos puede ser unafuente importante de iones. Así, por ejemplo, las zonas habitadas por humanos pueden ser ricas en cloruros y nitratos; hay cloruros en la comida y excrementos de hombres y animales. Los microorganismos producen nitratos a partir de excrementos y residuos. De todos modos, así como los nitratos tienen una clara fuente biológica, ésta no es tan segura para los cloruros (Arnold y Zehnder, 1989).

También la presencia de sales fosfatadas puede ser indicadora de acción biológica.

Los fosfatos y ácidos úricos del guano pueden causar la alteración de los minerales, conduciendoa la formación de sales fosfatadas de magnesio y calcio (Keys y Williams, 1981).

Los oxalatos de calcio, pueden ser derivados de la actividad metabólica de varias especies de líquenes, pero también pueden ser derivados de tratamientos antiguos de protección de la piedra (Lazzarini y Laurenzi-Tabasso, 1986).

Los sulfatos también pueden tener un origen microbiológico. Hay algunos micro-organismos capaces

\footnotetext{
${ }^{l}$ Nota de los autores: La formación final de $\mathrm{CaSO}_{4} \mathrm{2H}_{2} \mathrm{O}$ por reacción del $\mathrm{SO}_{2}$ atmosférico con el $\mathrm{CaCO}_{3}$ de los materiales y las reacciones intermedias son actualmente motivo de discusión. El mecanismo aqui recogido no es el único posible. Éste variará dependiendo, en gran medida, de la forma de depositarse el $\mathrm{SO}_{2}$ sobre los materiales.
} 
de metabolizar formas reducidas del azufre y oxidarlas a sulfatos, así como otros capaces de producir sulfuros. Estos organismos están a menudo presentes en piedras, principalmente calcáreas y en morteros a base de carbonato de calcio (Teutonico, 1988).

En resumen, las sales presentes en los monumentos pueden tener varios orígenes, siempre hay que estudiar cada caso en particular, correlacionando la naturaleza de las sales detectadas con las características y agentes medioambientales (agua, vientos...), de las piedras y de la edificación.

Así por ejemplo, Fassina(1978) estudiando costras negras en Venecia, estableció, en este caso concreto, los siguientes orígenes para los iones:

- Cationes: calcio, procedente de las rocas calcáreas; sodio, potasio y magnesio, origen marino o de la laguna.

- Aniones: carbonatos y silicatos, origen natural, de las rocas o arena transportada por el viento; nitratos, oxalatos y fosfatos, génesis biológica; sulfatos y cloruros, génesis mixta, industrial (principalmente los sulfatos) y natural (predominantemente los cloruros).

En la 'Tabla III, se exponen algunos orígenes probables de diversos iones que forman las sales

\section{4.-DAÑOS OCASIONADOS POR LAS SALES SOLUBLES EN LAS PIEDRAS DE LOS MONUMENTOS}

La cristalización de sales solubles en los poros de los materiales es a menudo una causa importante de su deterioro. El efecto de la cristalización de sales solubles es debido a una combinación de factores entre los que cabe citar, por una parte, el tipo y propiedades de sal (cambios de solubilidad con la temperatura, coeficiente de expansión térmica...), su concentración y el grado de sobresaturación alcanzado; y, por otra parte, las propiedades del material rocoso como el tamaño y distribución de los espacios vacíos u otras discontinuidades, la capacidad de absorción de agua, la resistencia mecánica, etc. (Goudi et al, 1970; Schaffer, 1972).

El deterioro debido a la cristalización de sales solubles, puede producirse por varios mecanismos. Es un proceso complejo y en muchas ocasiones es difícil establecer cuál de ellos es el predominante.

La mayoría de los autores consideran la existencia de una serie de mecanismos de distinta naturaleza, tales como:

.La cristalización. Las sales cristalizan a partir de una solución sobresaturada. Esta cristalización puede continuar incluso frente a presiones considerables de confinamiento. El empuje del cristal al crecer en un poro o fisura produce tensiones locales que tienden a agrandar dichos espacios vacíos. El deterioro se produce cuando las tensiones superan la resistencia a la tracción de la roca. La cristalización continúa hasta que el esfuerzo alcanza una magnitud determinada relacionada directamente con el grado de sobresaturación e inversamente con la solubilidad de la sal (Evans, 1970).

La hidratación. Existen sales que pueden presentar diferentes estados de hidratación (ej.: $\mathrm{MgSO}_{4} \cdot \mathrm{H}_{2} \mathrm{O}$; $\mathrm{MgSO}_{4} \cdot 6 \mathrm{H}_{2} \mathrm{O}, \mathrm{MgSO}_{4} .7 \mathrm{H}_{2} \mathrm{O}$ ). Estas sales, una vez cristalizadas al variar las condiciones de humedad y temperatura, pueden tomar o liberar agua de hidratación. Cuando se hidratan pueden desarrollar presiones en las paredes de los poros que pueden conducir al deterioro de la piedra que las contiene.

Estos dos tipos de mecanismos, son los más comúnmente aceptados por los autores como causantes del deterioro por sales. (Winkler y Wilhelm, 1970; Winkler y Singer, 1972; Winkler, 1973; Binda et al, 1985; Lazzarini y LaurenziTabasso, 1986, etc.).

. Otra causa de deterioro, relacionada, en parte, con la hidratación-deshidratación es la citada por Pühringer (1983): son cambios estructurales en la sal. Las sales depositadas no son cristales ideales, son formaciones salinas de textura porosa fina. En estas formaciones salinas pueden producirse cambios estructurales (que pueden ser debidos a hidratación y deshidratación parcial) debidos a cambios en las condiciones de humedad y temperatura, que pueden conducir a la ruptura del material del substrato. Pühringer, se apoya en que rocas que aparecen muy deterioradas, no presentan necesariamente un contenido alto en sales, y en base a esto rechaza la interpretación del daño como cambio de volumen de las 
TABLA III

\begin{tabular}{|c|c|c|c|}
\hline Iones & Alteración de materiales & Productos atmosféricos & Acción organismos vivos \\
\hline \multicolumn{4}{|l|}{ Cationes: } \\
\hline calcio & $\begin{array}{l}\text { *** Rocas calcáreas } \\
\text { (mármoles, calizas y } \\
\text { dolomías) }\end{array}$ & & \\
\hline sodio & $\begin{array}{l}* * * \text { materiales alcalinos } \\
\text { utilizados en edificios } \\
* \text { alteración de } \\
\text { feldespatos }\end{array}$ & $* * *$ origen marino & \\
\hline magnesio & $\begin{array}{l}\text { *** alteración de } \\
\text { minerales máficos } \\
* * \text { alteración de } \\
\text { feldespatos } \\
\text { ** alteración de } \\
\text { dolomita }\end{array}$ & $* *$ origen marino & \\
\hline potasio & $\begin{array}{l}\text { *** materiales alcalinos } \\
\text { utilizados en edificios } \\
\text { ** alteración de } \\
\text { feldespatos }\end{array}$ & * origen marino & \\
\hline \multicolumn{4}{|l|}{ Aniones: } \\
\hline sulfato & & $\begin{array}{l}* * * \text { atmósferas } \\
\text { contaminadas } \\
* \text { origen marino }\end{array}$ & \\
\hline cloruro & & $\begin{array}{l}* * * \text { origen marino } \\
* \text { atmósferas } \\
\text { contaminadas }\end{array}$ & * origen biológico \\
\hline carbonato & $\begin{array}{l}\text { *** alteración de rocas } \\
\text { carbonatadas } \\
\text { (mármoles, calizas y } \\
\text { dolomías) }\end{array}$ & $\begin{array}{l}\text { * atmósferas } \\
\text { contaminadas }\end{array}$ & \\
\hline nitrato & & $\begin{array}{l}\text { ** atmósferas } \\
\text { contaminadas } \\
* \text { origen marino }\end{array}$ & $* * *$ origen biológico \\
\hline oxalato & & & $* * *$ origen biológico \\
\hline
\end{tabular}

Orígenes de iones en rocas monumentales (Grossi 1992).

\footnotetext{
*** orígenes de cationes y aniones más citados por los autores consultados.

** orígenes de iones frecuentemente citados por los autores.

* posible origen de iones según diversos autores.
} 
sales que "rellenan" el espacio poroso. Delgado-Rodrigues (1991) está de acuerdo con esta hipótesis.

Cooke y Smalley (1968), propusieron también como mecanismo de deterioro, la expansión térmica diferencial de las sales con respecto al substrato rocoso que las soporta.

El deterioro de las piedras por sales, aparte de poder ser una combinación de estos mecanismos, suele ser un proceso cíclico. Se necesitan, por lo general, varios ciclos de cristalización-disolución o hidratación-deshidratación para que la roca se deteriore (Amoroso y Fassina, 1983, Binda et al, 1985).

Los daños ocasionados por los distintos tipos de sales y su distribución en los edificios

Sulfatos: Los más frecuentes son el $\mathrm{CaSO}_{4} \cdot 2 \mathrm{H}_{2} \mathrm{O}$ y el $\mathrm{Na}_{2} \mathrm{SO}_{4}$ con diferentes estados de hidratación (Amoroso y Fassina, 1983; Arnold, 1976); menos frecuentes son el $\mathrm{MgSO}_{4}$ y el K $\mathrm{SO}_{4}$

Según Amoroso y Fassina, el daño producido por los sulfatos no es debido a su solubilidad en agua, sino a su propiedad de cristalizar en diferentes estados de hidratación ( $\mathrm{Na}_{2} \mathrm{SO}_{4} .10 \mathrm{H}_{2} \mathrm{O}$ : mirabilita- $\mathrm{Na}_{2} \mathrm{SO}_{4}$ : thenardita; $\mathrm{MgSO}_{4} \cdot 7 \mathrm{H}_{2} \mathrm{O}$ : epsomita - $\mathrm{MgSO}_{4} \cdot \mathrm{H}_{2} \mathrm{O}$ : kieserita; $\mathrm{CaSO}_{4} \cdot 2 \mathrm{H}_{2} \mathrm{O}$ : yeso-CaSO ${ }_{4}$ : anhidrita). Estas sales pueden presentarse en estado anhidro o hidratado dependiendo de las condiciones de temperatura y de humedad relativa.

Cada estado de hidratación está caracterizado por un volumen específico, por tanto cada vez que se produce una transformación, tiene lugar un cambio de volumen.

Los sulfatos son en general menos solubles y móviles que otras sales, solamente pueden moverse cuando aún están en disolución. Precipitan en forma hidratada y posteriormente pueden transformarse en sales anhidras. Si una vez anhidras, la humedad no es muy alta, las sales no se disuelven, sino que se hidratan, ejerciendo una presión en las paredes de los poros.

En concreto, en el caso del el sulfato de sodio, el hidrato se produce a $\mathrm{T}$ por debajo de $32,4^{\circ} \mathrm{C}$. La hidratación $\mathrm{y}$ deshidratación de este sulfato, según la reacción:

$$
\mathrm{Na}_{2} \mathrm{SO}_{4} \cdot 10 \mathrm{H}_{2} \mathrm{O}+\text { vapor } \leftrightharpoons \mathrm{Na}_{2} \mathrm{SO}_{4}+\text { vapor }
$$

produce un deterioro importante (Arnold, 1976).

Según Winkler y Wilhelm (1970), la hidratación del sulfatode magnesio monohidrato (kieserita) a heptahidrato (epsomita) puede producirse en un solodía; y la hidratación y deshidratación del sulfato de sodio puede producirse varias veces al día causando que bajas presiones de hidratación afecten a la roca de manera importante. Otros autores señalan, sin embargo, que la hidratación del $\mathrm{MgSO}_{4}$ es más rápida que la del sulfato de sodio (Kwaad, 1970; ASTM, 1977). La deshidratación de la mirabilita a $39^{\circ} \mathrm{C}$ no dura más de 20 minutos; sin embargola hidratación es un proceso más lento (Arnold, 1976; Charola y Weber, 1992).

Carbonatos: El más importante es el carbonato de sodio. Forma dos hidratos diferentes: $\mathrm{Na}_{2} \mathrm{CO}_{3} \cdot 10 \mathrm{H}_{2} \mathrm{O}$ (natritra) y $\mathrm{Na}_{2} \mathrm{CO}_{3} \cdot \mathrm{H}_{2} \mathrm{O}$ (termonatrita). A temperaturas por debajo de $32^{\circ} \mathrm{C}$ precipita como decahidrato. El comportamiento de esta sal es similar a la del sulfato de sodio y el deterioro producido también puede ser similar (Arnold, 1976; Amoroso y Fassina, 1983). Según Kwaad (1970) la hidratación del $\mathrm{Na}_{2} \mathrm{CO}_{3}$ es más rápida que la del sulfato de sodio. Winkler y Wilhelm (1970) señalan que la hidratación del carbonato de sodio, a bajas temperaturas y alta humedad, puede desarrollar el esfuerzo necesario para destruir la roca.

Cloruros: Los más comunes son el $\mathrm{NaCl}$ (halita), $\mathrm{KCl}$ (silvita) y $\mathrm{CaCl}_{2} \cdot 6 \mathrm{H}_{2} \mathrm{O}$ (antarcticita) (Amoroso y Fassina, 1983). Según estos autores son extremadamente peligrosos, ya que son muy solubles e higroscópicos. En solución son muy móviles y pueden penetrar profundamente. Su acción agresiva es debida principalmente a la cristalización y la forma de alteración predominante es la pulverización.

En cuanto al grado de alteración inducido por las distintas sales, Lewin (1989) señala que para un deterioro por sales se necesita una tendencia a la sobresaturación: "un soluto depositado bajocondiciones de equilibrio no libera ninguna energía y no ejerce trabajo mecánico".

En general, según este autor, cuanto mayor es la solubilidad de una sustancia, mayor es su tendencia a la sobresaturación. En la Tabla IV se exponen las tendencias 
a la sobresaturación de algunas sales.

Para este autor, la cristalización del sulfato de sodio decahidratado es un caso especial. Esta sal se utiliza normalmente en los ensayos de cristalización en el laboratorio. Según él, es menos efectivo que el $\mathrm{NaCl}$ si cristaliza a una temperatura ambiente de $20-25^{\circ} \mathrm{C}$. Sin embargo, a la temperatura del ensayo en el laboratorio $\left(60^{\circ} \mathrm{C}\right.$ generalmente) la fase que se deposita es un hidrato menor o anhidro que al transformarse en decahidrato constituye un fuente de liberación de energía libre capaz de deteriorar la piedra.

Para Auger (1989), el deterioro causado por la mayoría de las sales solubles es debido a la presión que ejercen los cristales al crecer en el seno de la roca que los alberga. Las presiones vienen condicionadas por las características de la sal. Así se atribuye el máximo efecto:

- A la cristalización de sales anhidras ( $\mathrm{Ej}: \mathrm{NaCl})$.

- Al paso de forma anhidra a hidratada ( $\mathrm{Ej}: \mathrm{MgCl})$.

- A las variaciones de solubilidad ( $\left.\mathrm{Ej}: \mathrm{Na}_{2} \mathrm{SO}_{4}\right)$.

- A la higroscopicidad (Ej: $\mathrm{NaCl})$.

Todos estos condicionantes son causas de deterioro por separado o conjuntamente, pero según la naturaleza de la sal dominará uno u otro.

Para Charola y Lewin (1979), el efecto destructivo del sulfato de sodio, que se atribuye a menudo a la expansión volumétricaqueacompañaala hidratación-deshidratación de la sal, no tiene porqué ser debido a este efecto. En condiciones naturales se deposita el $\mathrm{Na}_{2} \mathrm{SO}_{4} \cdot 10 \mathrm{H}_{2} 0$ que no tiene porqué ser más destructivo que el de otra sal anhidra en la misma cantidad ( $\mathrm{Ej}: \mathrm{NaCl})$. Es el número de núcleos formados y su crecimiento lo que determina la magnitud de las presiones ejercidas y no el volumen específico del sólido.

Arnold y Zehnder (1985) también señalan que la cristalización de sales hidratadas no tiene porqué causar más daño que la de las sales anhidras.

Binda et al (1985) indican que el deterioro depende tanto del tipo de sal como de las condiciones de crecimiento del cristal. Comparando cloruro sódico, sulfato sódicoy sulfato magnésico indican que la temperatura y humedad en las etapas de secado en ensayos de cristalización de sales, condicionará los hábitos en los que crecen los cristales, dando lugar a distintos tipos de deterioro. Por otra parte, el menor grado de deterioro encontrado con el cloruro sódico respecto a las otras dos sales, lo atribuyen fundamentalmente a la posibilidad de cambios en los estados de hidratación de estas dos últimas, especialmente en el sulfato sódico.

Además, etapas de secado largas para los tres tipos de sales, conducen a un mayor deterioro, ya que se puede formar un número de cristales más elevado, éstos pueden crecer más y también posibilitaría la aparición de

TABLA IV

\begin{tabular}{||c|c|c||}
\hline Sustancia & $\begin{array}{c}\text { Solubilidad } \\
(\mathbf{g} / \mathbf{1 0 0} \mathbf{~ m l})\end{array}$ & $\begin{array}{c}\text { Tendencia a la } \\
\text { sobresaturación }\end{array}$ \\
\hline $\mathrm{NaCl}$ & 37 & ++ \\
$\mathrm{NaNO}_{3}$ & 110 & ++ \\
$\mathrm{Na}_{2} \mathrm{CO}_{3} \cdot 7 \mathrm{H}_{2} \mathrm{O}$ & 32 & + \\
$\mathrm{Na}_{2} \mathrm{SO}_{4} \cdot 10 \mathrm{H}_{2} \mathrm{O}$ & 93 & + \\
$\mathrm{MgCl}_{2} \cdot 6 \mathrm{H}_{2} \mathrm{O}$ & 200 & ++ \\
$\mathrm{MgSO}_{4} \cdot 7 \mathrm{H}_{2} \mathrm{O}$ & 71 & muy pequeña \\
$\mathrm{CaSO}_{4} \cdot 2 \mathrm{H}_{2} \mathrm{O}$ & 0,23 & + \\
$\mathrm{KCl}$ & 35 & + \\
\hline
\end{tabular}

Tendencia a la sobresaturación de algunas sales presentes en monumentos (Lewin, 1989). En esta tabla, el autor no hace mención a la temperatura. 
cristalizaciones secundarias, que agravarían el deterioro. Concluyen que el deterioro por sales estaría influenciado por: 1) Ciclos de hidratación-deshidratación que sufre la sal (debido fundamentalmente a la aparición de una cristalización secundaria, durante la deshidratación); 2) Número de núcleos de cristales formados, y c) La cantidad de tiempo que los cristales tienen para crecer.

Para Evans (1970), el factor más importante es la cristalización. Señala que los experimentos de Kwaad en 1970 sobre granito pusieron de manifiesto la importancia del crecimiento de cristales en condiciones donde el cambio de temperatura era poco importante, y por tanto, la hidratación imposible; el sulfato de magnesio y el carbonato de sodio, que se pueden hidratar en un día, son menos efectivos que el sulfato de sodio cuya hidratación es más lenta. El cloruroes menos dañino inclusoa temperatura constante. El efecto del sulfato de sodio es mucho mayor con las variaciones de temperatura, ya que su solubilidad cambia mucho con la misma. Para este autor la efectividad relativa de las sales sería: 1) $\mathrm{Na}_{2} \mathrm{SO}_{4}$;2) $\mathrm{Na}_{2} \mathrm{CO}_{3}$; 3) $\left.\mathrm{MgSO}_{4} 4\right) \mathrm{NaCl}$. Goudi, et al (1970), también encontraron esta secuencia excepto para el carbonato de sodio. Estos autores realizaron ciclos de cristalización, simulando condiciones desérticas, en una arenisca con varios tipos de sales. Llevaron a cabo 40 ciclos con las siguientes etapas: inmersión (una hora a $17^{\circ} \mathrm{C}$ ), secado (6 horas a $60^{\circ} \mathrm{C}$ ) y enfriamiento (hasta completar las 24 horas a $30^{\circ} \mathrm{C}$ ), con soluciones saturadas de diversas sales. Encontraron que tanto con el $\mathrm{MgSO}_{4}$ como con el $\mathrm{Na}_{2} \mathrm{SO}_{4}$ la roca sufría una pérdida de peso considerable ya en el ciclo 10 , mientras que con el $\mathrm{NaCl}$ y $\mathrm{Na}_{2} \mathrm{CO}_{3}$ no se observaba disminución. La opinión de los autores de esta revisión bibliográfica (Grossi y Esbert) coincide con la expresada por Evans (1970); Kwaad (1970) y Goudi et al (1970). La diferencia en el comportamiento del $\mathrm{Na}_{2} \mathrm{CO}_{3}$, en ambos casos, puede ser debida a variaciones en las condiciones del ensayo.

Como la mayoría de los estudios de laboratorio con sales solubles son con sulfato de de sodio y magnesio y cloruro de sodio, la mayoría de los autores encuentran que la sal más dañina es el sulfato de sodio; la segunda en importancia sería el sulfato de magnesio y la tercera el cloruro de sodio (Binda et al, 1985; Smith y McGreevy, 1988; Alcalde y Martín, 1990...); aunque debe tenerse en cuenta que el cloruro de sodio es importante en el deterioro de monumentos en zonas desérticas (Gauri et al, 1988,....) y ambientes marinos.

En cuanto a su aparición en los edificios, puede afirmarse, en general, que aquellas paredes en las que aparecen sales solubles en el interior de sus materiales, presentan diferentes grados de alteración según la sal correspondiente. En distintas zonas de la pared habrá diferentes sales, dependiendo de la humedad, de la solubilidad y de la movilidad de las mismas.

Así Arnold y Zehnder (1989) establecen un perfil de cristalización de sales en las paredes verticalmente según el contenido en humedad de la misma, distinguiendo cuatro niveles $\mathrm{A}, \mathrm{B}, \mathrm{C}$ y D.

Nivel A: Más próximo al suelo, más húmedo, presenta un deterioro menor al del nivel $\mathrm{B}$ y las sales solamente precipitan ocasionalmente.

Nivel B: Presenta desagregación granular, desmoronamiento, descamación..., es donde aparecen la mayor parte de las eflorescencias. Las sales presentes son, principalmente, sulfato de sodio, sulfato de magnesio, nitrato de potasio y también carbonato de sodio, correspondiendo al grupo de sales de solubilidad baja a moderada.

Nivel C: Poco deteriorado. Húmedo. En este nivel localmente se pueden concentrar y acumular cloruros y nitratos. Debido a que la mezcla de iones de esta zona son extremadamente higroscópicos, estas sales no suelen cristalizar en las paredes de edificios de climas templados.

El nivel D no presentaría alteración.

En resumen, los sulfatos y carbonatos, menos solubles, causan el mayor deterioro en las zonas A y B, en paredes exteriores de climas templados, mientras que la zona $\mathrm{C}$ suele ser una zona poco dañada. En esta zona $C$ se acumulan los cloruros y nitratos que forman una solución higroscópica, y donde sólo cristaliza el nitrato de potasio y excepcionalmente el cloruro de sodio y el nitrato de sodio, cuando las condiciones externas se vuelven muy secas.

En la Tabla $\mathrm{V}$ se indican las humedades relativas de equilibrio, a $20^{\circ} \mathrm{C}$ de algunas sales solubles (Arnold y Zehnder, 1988): 
TABLA V

\begin{tabular}{|c|c|}
\hline & $\mathrm{HR}(\%)$ \\
\hline Natrita $\mathrm{Na}_{2} \mathrm{CO}_{3} \cdot 10 \mathrm{H}_{2} \mathrm{O}$ & 97,7 \\
\hline Nitrokalita $\mathrm{KNO}_{3}$ & 94,6 \\
\hline Mirabilita $\mathrm{Na}_{2} \mathrm{SO}_{4} \cdot 10 \mathrm{H}_{2} \mathrm{O}$ & 93,6 \\
\hline Epsomita $\mathrm{MgSO}_{4} \cdot 7 \mathrm{H}_{2} \mathrm{O}$ & 90,1 \\
\hline Nitronatrita $\mathrm{NaNO}_{3}$ & 75,4 \\
\hline Nitromagnesita $\mathrm{Mg}\left(\mathrm{NO}_{3}\right) \cdot 6 \mathrm{H}_{2} \mathrm{C}$ & 54,4 \\
\hline Halita $\mathrm{NaCl}$ & 75,5 \\
\hline
\end{tabular}

Humedades relativas de equilibrio a $20^{\circ} \mathrm{C}$ de algunas sales solubles.

Horizontalmente en las paredes, de las zonas externas a las internas, también se puede encontrar una distribución similar.

Así, Auger(1989) en un monumentoantiguode la Rochelle (Francia)construido con caliza encuentrauna distribución de yeso y halita que se expone en la Tabla VI.
El mismo autor, simulando una atmósfera marina durante tres meses, también observó una acumulación de sulfatos en la superficie y una distribución de cloruros por toda la masa (Tabla VII).

Así los sulfatos que no son muy solubles permanecen en la superficie, mientras que los cloruros que se mueven

TABLA VI

\begin{tabular}{|c|c|c|c|}
\hline \multirow[t]{2}{*}{ Piedra } & \multirow[t]{2}{*}{ profundidad en $\mathrm{cm}$} & \multicolumn{2}{|c|}{ Concentración en mg por $100 \mathrm{~g}$ de roca seca } \\
\hline & & $\mathrm{NaCl}$ & $\mathrm{CaSO}_{4}$ \\
\hline \multirow{5}{*}{ Caliza de grano fino } & 0,0 a 1,0 & 883 & 453 \\
\hline & 1,0 a 3,5 & 768 & 0 \\
\hline & 3,5 a 5,5 & 724 & 0 \\
\hline & 5,5 a 8,0 & 730 & 0 \\
\hline & 8,0 a 10 & 738 & 0 \\
\hline
\end{tabular}

Distribución de halita y yeso, de de la parte exterior a la interior, en una pared de caliza de un monumento de la Rochelle.

TABLA VII

\begin{tabular}{||c|c|c|c|}
\hline \multirow{2}{*}{ Piedra } & \multirow{2}{*}{ Profundidad en cm } & \multicolumn{2}{|c|}{ Concentración en mg por 100 g de roca seca } \\
\cline { 3 - 4 } & & $\mathrm{NaCl}$ & $\mathrm{CaSO}_{4}$ \\
\hline \multirow{2}{*}{ Caliza } & Costra superficial & 907 & 1479 \\
& Algunos mm hacia el & 1433 & 444 \\
& interior & & \\
\hline
\end{tabular}

Distribución de halita y yeso en una caliza francesa una vez expuesta a una simulación de atmósfera marina. 
más fácilmente pueden migrar más, antes de alcanzar el punto de saturación.

Smith y McGreevy (1988), en ensayos de alterabilidad en el laboratorio con $\mathrm{MgSO}_{4}, \mathrm{Na}_{2} \mathrm{SO}_{4}$ y $\mathrm{NaCl}$, también encontraron que los sulfatos tienden a concentrarse, en ciertas zonas de la probeta, mientras que los cloruros se encuentran diseminados por toda ella.

\section{AGRADECIMIENTOS}

A la Comisión Interministerial de Ciencia yTecnología(CICYT), Proyectos : PAT-85-0488 y PAT 91- 1093-C03-01.

Al Ministerio de Educación y Ciencia -Secretaría de Estado de Universidades e Investigación- por la financiación de la investigación titulada: "Interacción de los productos de contaminación atmosférica y los materiales carbonatados de edificación: Variaciones de su microestrutura y propiedades físicas".

\section{BIBLIOGRAFÍA}

ALCALDE, M. y MARTÍN, A. (1990).- "Morfología macroscópica de alteración acelerada de algunos materiales pétreos de monumentos de Andalucía - España". Materiales de Construcción, Vol. 40, n²18, pp. 5-27.

ALONSO, F.J. (1986).- “Caracterización petrofísica y alterabilidad de calizas y dolomías”. Tesis Doctoral. Dpto. de Petrología y Geoquímica. Fac. de Geología. Universidad de Oviedo, 309 p.

ALONSO, F.J.; ORDAZ, J.; VALDEÓN, L. y ESBERT, R.M. (1987).- "Revisión crítica del ensayo de cristalización de sales". Materiales de Construcción, Vol. 37, $n^{\circ}$ 206, pp. 53-60.

AMOROSO, G.G. y FASSINA, V. (1983).- "Stone decay and conservation. Atmospheric pollution, cleaning, consolidation and protection". Material Science Monographs. Edit: Elsevier, 453 pp.

ARNOLD, A. (1976).- "Behaviour of some soluble salts in stone monuments". 2nd International Symposium on the Deterioration of Building Stones, Atenas, pp. 27-36.

ARNOLD, A. (1981).- "Nature and reactions of saline minerals in walls". The Conservation of Stone II. International Symposium, Bolonia, pp. 13-23.

ARNOLD, A. y KUENG, A. (1985).- "Crystallization and habits of salt efflorescences on walls, I". Vth International Congress on Deterioration and Conservation of Stone, Lausanne, pp. 255-267.

ARNOLD, A. y ZEHNDER, K. (1985).- "Crystallization and habits of salt efflorescences on walls II". Vth International Congress on Deterioration and Conservation of Stone, Lausanne pp. 269-277.

ARNOLD, A. y ZEHNDER, K. (1988).- "Decay of stony materials by salts on humid atmospheres". VIth Int. Congress on Deterioration and Conservation of Stone. Torun, pp. 138-148.

ARNOLD, A. y ZEHNDER, K. (1989).- "Salt weathering on monuments". The Conservation of Monuments in the Mediterranean Basin, Bari, pp. 31-58.

A.S.T.M. (C-88) (1977).- "Standard test method for: Soundness of aggregates by use of sodium sulfate or magnesium sulfate". Annual Book of ASTM Standars. Part 14. American Society for Testing and Materials, pp. 48-53. 
AUGER, F. (1989).- "World limestone decay under marine spray conditions". The Conservation of Monuments in the Mediterranean Basin, Bari, pp. 65-69.

BINDA, L. y BARONIO, G. (1984).- "Measurement of the resistance to deterioration of old and new bricks by means accelerated aging tests". Durability of Building Materials, Vol. 2. n² 2. Edit: Elsevier, pp. 139-154.

BINDA, L. y BARONIO, G. (1987).- "Mechanisms of masonry decay due to salt crystallization". Durability of Building Materials, pp. 227-240.

BINDA, L.; BARONIO, G. y CHAROLA, A.E. (1985).- "Deterioration of porous materials due to sal crystallization under different thermohygrometric conditions, I Brick". Vth International Congress on Deterioration and Conservation of Stone, Lausanne, pp. 279-288.

COOKE, R.V. y SMALLEY, I.J. (1968).- "Salt weathering in deserts". Nature V 220, p. 1226-1227.4 pp. 227-240.

CUTTANO, M.; MASTRONARDI, P. y ROSSI-MANARESI, R. (1981).- “Alveolar weathering of the "tuff” of Matera. Mechanism of deterioration and effectiveness of preservative treatments". The Conservation of Stone, II. International Symposium, Bolonia, pp. 355-377.

CHAROLA, A.E. y LEWIN S.Z. (1979).- "Examples of stone decay due to salt efflorescence". 3rd Int. Congress on the Deterioration and Preservation of Stones (Venecia), pp. 153-163.

CHAROLA, A.E. y WEBER, J. (1992).- "The hydration-dehydration mechanism of sodium sulphate". 7th International Congress on Deterioration and Conservation of Stone", Lisboa, pp. 581-589.

CHATERJII, S.; CHISTENSEN, P. y OVERGARD, G. (1979).- "Mechanisms of breakdown of natural stones caused by sodium salts". 3rd International Congress on Deterioration and Preservation of Stones, Venecia, pp. 131-134.

DE TOMMASI, G.B. y LAURENZI-TABASSO, M. (1989).- "La Cattedrale di Trani: influence di condizioni ambientali controllate sul degrado del paramento interno". La Conservazione dei Monumenti nel Bacino del Mediterraneo, Bari, pp. $397-406$.

DELGADO RODRIGUES, J. (1991).- "Causes, mechanisms and measurement of damage in stone monuments". Science Technology and European Cultural Heritage. Commission of the European Communities, pp. 124-137.

DEJOU, J.; GUYOT, J. y ROBERT, M. (1977).- "Evolution superficielle des roches cristallines et cristallophylliennes dans les régions tempérées". Institut National de Recherche Agronomique, 464 pp.

ESBERT R.M. y MARCOS R.M. (1983).- "Las piedras de la Catedral de Oviedo y su deterioración”. Colegio Oficial de Aparejadores y Arquitectos Técnicos de Asturias. $147 \mathrm{p}$.

EVANS, I.S. (1970).- "Salt crystallization and rock weathering: a review". Revue de Géomorphologie dynamique, XIX Année, nº 4 , pp. 153-177.

FASSINA, V. (1978).- "A survey of air pollution and deterioration of stonework in Vencice". Atmospheric Environment, V.12, pp. 2205-2211

FRITSCH, H.; SCHAMBERG, E.: POZZI, E. (1988).- "Protezione dei materiali lapidei dal danneggiamento causato dai sali". Recuperare. Anno 7, n 35. Edit. Peg. Propaganda Edit Grafica (Milán) pp. 331-335. 
FURLAND, V. y FÉLIX, C. (1982).- "La Dégradation de la Pierre et les Moyens de Protection”. Chimia, 36. n 7/8, pp. 313-318.

GAURI, K.L. (1981).- "The deterioration of ancient stone structures in Egypt". Pospection et Sauvegarde des Antiquités de L'Égypte. Inst. Francais d'Arquéologie Orientale du Caire. Edit. N.Ch. Grimal, pp.13-18.

GAURI, K.L; CHAWCHURY, A.N.; KUSHRESHTHA, N.P. y PUNURU, A.R. (1988).- "Geologic features and the durability at the Sphinx". Eng Geol. of Anc. Works, Monuments and Hist. Sites. Balkema, Rotterdam, pp. 723-729

GOUDI , A.; COOKE, R.U. y EVANS, I.S. (1970).- "Experimental investigation of rock weathering by salts". Area, nº4.; pp. 4248.

GROSSI, C.M. (1992).- "Cristalización de sales en rocas monumentales porosas y su auscultación mediante emisión acústica". Tesis Doctoral. Area de Petrología. Dep. de Geología. Universidad de Oviedo, 261 pp.

KEYS, J.R. y WILLIAMS, K. (1981).- "Origin of crystalline, cold desert salts in the McMurdo region, Antarctica". Geochimica et Cosmochimica Acta. Vol. 45, pp. 2299-2309.

KWAAD, F.J.P.M. (1970).- "Experiments on the granular disintegration of granite by salts action". Field to Laboratory, publ. 16. Univ. Amsterdam, Fysich Geogr. en Bodemkundig laboratorium, pp. 67-80.

LAZZARINI, L. y LAURENZI-TABASSO, M. (1986).- "Il Restauro della pietra". CEDAM. Edit. Dott. Antonio Milani, Padova, $320 \mathrm{p}$.

LEWIN, S. (1981).- "The mechanism of masonry decay through crystallization". Conservation of Historic Stone Buildings and Monuments. National Academy of Sciences (Washington), 31 p.

LEWIN, S. (1989).- "The susceptibility of calcareous stones to salt decay". The Conservation of Monuments in the Mediterranen Basin, Bari, pp. 59-63.

MAGEE, A.W.; BULL, P.A. y GOUDIE, A.S. (1988).- "Chemical Textures on Quartz grains: an experimental approach using salts". Earth Surface Processes and Landforms, Vol. 13, pp. 665-676.

MATSUKURA, Y. y KANAI, H. (1988).- "Salt fretting in the Valley Cliff of the Asama Volcano Region, Japan". Earth Surface Processes and Landforms, Vol. 13, pp. 85-90.

PÜHRINGER, J. (1983).- "Salt disintegration. Salt migration and degradation by salt - a hypothesis". Swedish Council for Building Research. Spangbergs Tryckerier AB, Stockholm, 159 p.

PRESS, F. y SIEVER, R. (1985).- “Weathering: the decomposition of rocks”. Earth, Cap. 5. Edit. Freeman, pp. 101-124.

ROSSI-MANARESSI, R. y TUCCI, A. (1990).- "Texture and Mechanical Disgregation of Tuffs from Italy and Ecuador". Lavas y Tobas Vocánicas (Isla de Pascua-Chile). Edit. A.E. Charola. pp. 141-150.

ROSSI-MANARESI, R. y TUCCI, A. (1991).- "Pore structure and the disruptive effect of salt crystallization in various types of stone". Studies in Conservation, 36, pp.53-58

SCHAFFER, R.J. (1972).- "The Weathering of Natural Building Stones". Building Research. Special Report N 18. pp. 69-73. 
SMITH, B.J. y MCGREEVY, J.P (1988).- "Contour scaling of a sandstone by salts weathering under simulated hot desert conditions". Earth Surface Processes and Landforms, Vol.13, pp. 697-705.

SPERLING, C.H.B. y COOKE, R.U. (1980).- "Salt weathering in arid environments I. Theoretical considerations". Papers in Geography. N.8. Bedford College. Rgent's Park, London, N.W.1 4NS, 45 p.

TEUTONICO, J.M. (1988).- “A laboratory manual for architectural conservations”. ICCROM, 168 pp.

WINKLER, E.M. (1973).- “Stone: Properties, Durability in Man's Environment”. Springer. Verlag (Nueva York), 230 pp.

WINKLER, E.M. y SINGER, (1972).- “Crystallization Pressure of salt in stone and concrete”. Geological Soc. of Am. Bull. pp. 3509-3514.

WINKLER, E.M. y WILHELM, E.J. (1970).- "Salt burst by Hydration Pressure in Architectural Stone in urban atmosphere".

Geol. Soc. America Bull. V.81, pp. 567-572.

YOUNG, A.R.M. (1987).- "Salt as an agent in the development of cavernous weathering". Geology, V.15, pp. 962-966.

ZHENDER, K. (1982).- "Verwitterung von Molassesandsteinen an Bauwerken und in in Naturaufschlüsen". Beitr. Geol. Schweiz Geotech. Ser. 61 .

ZHENDER, K. y ARNOLD, A. (1989).- “Crystal growth in salt efflorescence”. Journal of Crystal Growth, 97, pp.523-521.

\section{publicaciones del ICCET/CSIC}

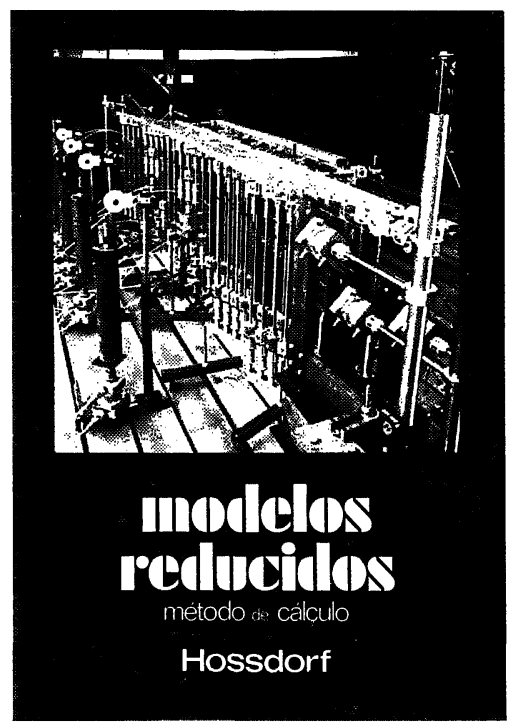

Modelos reducidos. Método de cálculo

H. Hossdorf, Ingeniero Civil

La técnica de los ensayos en modelos reducidos de estructuras sufre hoy día una decisiva metamorfosis. Hasta hace poco era un medio más bien de artesania, que no siempre era tomado en serio por los nia, que no siempre era tomado en serio por los miento resistente de las estructuras complejas y al que se acudió las más de las veces, como a un último remedio debido a sus indiscutibles insuficiencias. Sin embargo, en poco tiempo y gracias a su conexión con los ordenadores digitales, se ha transformado en un instrumento cientificamente valioso que no puede quedar a un lado en la práctica diaria del Ingeniero Proyectista.

Un volumen encuadernado en cartoné plastificado con lomo de tela, de $17 \times 24 \mathrm{~cm}$, compuesto de 250 páginas, 158 figuras y fotografias.

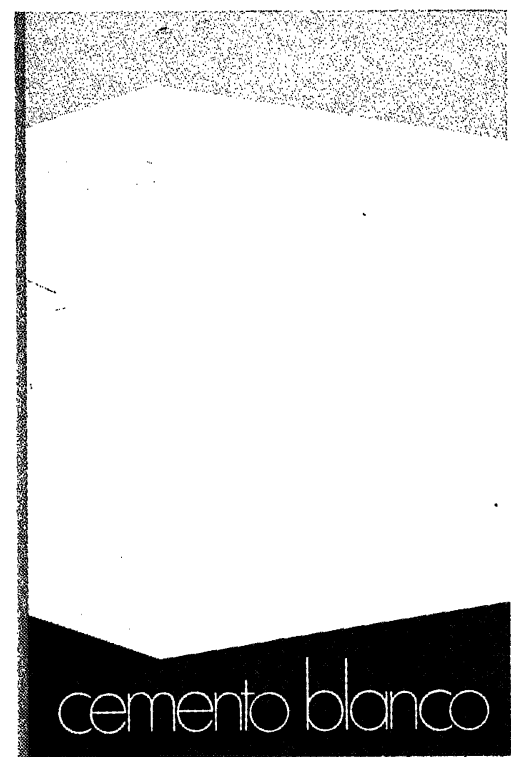

\section{Cemento blanco}

Juliản Rezola

Ingeniero Quimico Dipl. I. O. S

Sabido es que existe una extensa y documentada bibliografia sobre el cemento gris: en cambio, no puede decirse lo mismo acerca del cemento portland blanco, ya que los eschios existentes se refieren tan de aquél.

El autor nos ofrece sus profundos conocimientos y su larga experiencia tanto en laboratorio como en fabricación.

La parte descriptiva del libro se complementa con gráficos, diagramas y fotografias de gran utilidad, yuir la aplicación apropiada

Un volumen encuadernado en cartoné policerado, de $17,4 \times 24,3 \mathrm{~cm}$, compuesto de 395 páginas, numerosas figuras, tablas y ibbacos.

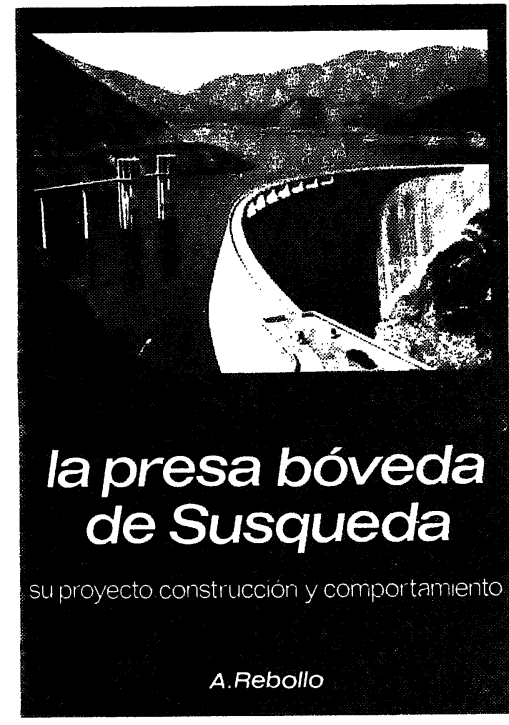

La presa bóveda de Susqueda

A. Rebollo,

Dr. Ingeniero de Caminos

El esfuerzo del constructor de presas se sitúa, por su pretensión de perennidad, a contracorriente de las tendencias de la civilización actual, caracterizada por to fungible. Pueden evocarse las 10.000 grandes presas en funcionamiento o en construcción grae presas en funcionamiento o en construccion que esto enveju $y$ re gervicio $y$ gar parzar su inalienable pretensión su perennida En la medida en que iadas nuevas perens, grandes o pequeñas, son portadoras de riesgos ecologicos $y$ a veces, catastróficos, que aumentan con el envejecimiento, la gerontologia que las presas es todo un emplazo. La acciön adelantada de Arturo Rebollo en este terreno marca un camino a seguir para todos los que aman su propia obra con la devoción paternal que è ha puesto en Susqueda.

Un voiumen encuadernado en cartoné plastificado con lomo de tela, de $18 \times 24,5 \mathrm{~cm}$, compuesto de 408 páginas, 330 figuras y fotografias y 39 tablas. 